\title{
Sisymbrium altissimum yapraklarının fenolik bileşen, antioksidan kapasite ve antidiyabetik özelliklerinin tespiti
}

\author{
Determination of phenolic component, antioxidant capacity, and antidiabetic properties of \\ Sisymbrium altissimum leaves
}

\author{
Mehmet Ali TEMIZ*1,a \\ ${ }^{1}$ Karamanoğlu Mehmetbey Üniversitesi, Teknik Bilimler Meslek Yüksekokulu, Tıbbi ve Aromatik Bitkiler Programı, 70100, Karaman
}

• Geliş tarihi / Received: $10.05 .2021 \quad$ •Düzeltilerek geliş tarihi / Received in revised form: 18.10.2021 • Kabul tarihi / Accepted: 27.10 .2021

\section{$\ddot{O} z$}

Diabetes Mellitus (Şeker hastalığı), yüksek kan glukozu (hiperglisemi) ile karakterize edilen ve tüm dünyada en çok muzdarip olunan hastalıklar arasındadır. Hiperglisemi oksidatif stresin oluşum mekanizmalarını tetikleyerek pek çok hastalığın patogenezinde rol oynar. Fitoterapi bu hastalıklar ile başa çıkmada alternatif yollardan biridir. Tıbbi, aromatik ve yabani yenilebilir bitkiler içerdikleri fitokimyasallar sayesinde nutrasötik olarak çeşitli hastalıklara karşı koruyucu etki göstermelerinin yanı sıra besleyici ve diyetetik özelliklere sahiptirler. Sisymbrium türleri yabani yenilebilir bitkiler arasında olup geleneksel olarak çeşitli hastalıkların tedavisinde kullanılmaktadır. Bu çalışmada, Sisymbrium altissimum yapraklarının fenolik bileşiminin yanı sıra antioksidan kapasitesinin ve antidiyabetik özelliklerinin araştırılması amaçlanmıştır. Bu maksatla S. altissimum yaprak ekstraktında (SAE) yüksek performanslı sıvı kromatografisi (HPLC) ile fenolik bileșen tespiti yapıldı. Ayrıca, antioksidan kapasitesini belirlemek amacıyla toplam fenolik ve toplam flavonoid madde tayini ile 2,2-difenil-1-pikrilhidrazil (DPPH) ve 2,2'-Azino-bis (3-etilbenzotiazolin-6-sülfonik asit) (ABTS) serbest radikal temizleme aktivite analizleri gerçekleştirildi. Yaprakların antidiyabetik etkisi, $\alpha$-amilaz ve $\alpha$-glukozidaz inhibisyon aktivite tayini ile ölçüldü. Elde edilen sonuçlarda, SAE'nin önemli düzeyde antioksidan aktivite gösterdiği belirlendi. Yapraklarda en çok bulunan fenolik bileşenin rutin olduğu ayrıca, kuersetin ve protokateşuik asidin ise yapraklardaki diğer baskın fenolik bileşenler olduğu saptandı. Diğer taraftan yaprakların $\alpha$-amilaz ve $\alpha$-glukozidaz inhibisyon aktivitelerinin akarboz ile karşılaştırıldığında daha düşük olduğu tespit edildi. Sonuç olarak, S. altissimum'um önemli fenolik bileşen içeriğiyle antioksidan durumu güçlendirebileceği ve ayrıca kısmi $\alpha$-amilaz ve $\alpha$-glukozidaz inhibisyon aktiviteleri sayesinde nutrasötik olarak yemek sonrası hiperglisemiyi önleyebileceği sonucuna varılabilir.

Anahtar kelimeler: Antioksidan aktivite, $\alpha$-amilaz, $\alpha$-glukozidaz, Fenolik bileşik, Sisymbrium altissimum

\begin{abstract}
Diabetes Mellitus is characterized by high blood glucose (hyperglycemia) and is among the most suffering diseases all over the world. Hyperglycemia plays a role in the pathogenesis of many diseases by triggering the mechanisms of oxidative stress. Phytotherapy is one of the alternative ways to cope with these diseases. Medicinal, aromatic and wild edible plants have nutraceutically protective effects against various diseases as well as nutritional and dietetic value due to the phytochemicals. Sisymbrium species are among the wild edible plants and traditionally used to treatment of various diseases. In this study, it was aimed to investigate the phenolic components of Sisymbrium altissimum leaves as well as their antioxidant capacity and antidiabetic properties. For this purpose, phenolic component was determined in S. altissimum leaf extract (SAE) by high performance liquid chromatography (HPLC). In addition, total phenolic and total flavonoid content measurement, 2,2-Diphenyl-1-picrylhydrazyl (DPPH) and 2,2-azinobis- (3-ethylbenzothiazoline-6sulphonic acid) (ABTS) free radical scavenging activity analyzes were performed to determine the antioxidant capacity. The antidiabetic effect of the leaves was measured by $\alpha$-amylase and $\alpha$-glucosidase inhibition activity assay. In the results obtained, it was determined that SAE showed a significant antioxidant activity. It was determined that the most abundant phenolic component in leaves was rutin, also quercetin and protocatechuic acid were the other dominant phenolic components in leaves. On the other hand, it was found that the $\alpha$-amylase and $\alpha$-glucosidase inhibition activities of the leaves were lower compared to acarbose. As a result, it can be concluded that $S$. altissimum can strengthen the antioxidant status with its important phenolic compounds and also prevent nutraceutically postprandial hyperglycemia due to its partial $\alpha$-amylase and $\alpha$-glucosidase inhibition activities.
\end{abstract}

Keywords: Antioxidant activity, $\alpha$-amylase, $\alpha$-glucosidase, Phenolic compound, Sisymbrium altissimum

\footnotetext{
${ }^{{ }^{*} a}$ Mehmet Ali TEMIZ; matemiz@kmu.edu.tr, Tel: (0338) 22620 00, orcid.org/0000-0002-4680-3023
} 


\section{Giriş \\ 1. Introduction}

Diabetes Mellitus, pankreas tarafindan yeterince insülin üretilememesi ve/veya üretilen insülinin etkili bir şekilde kullanılamaması sonucu ortaya çıkan yüksek kan glukozu (hiperglisemi) ile karakterize edilen heterojenik bir metabolik bozukluktur (Ferrier, 2017). Dünya genelinde 2016 y1lında tahmini olarak 1.6 milyon insan diyabetten dolay1 hayatını kaybetmiştir (WHO, 2020). Hiperglisemi; kardiyovasküler hastalıklar, yüksek tansiyon, nöropati, nefropati, retinopati, ayak hasarı ve cilt problemleri gibi başlıca diyabetik komplikasyonların oluşumunu tetiklemektedir (WHO, 2016). Hipergliseminin neden olduğu enzimatik olmayan glikozilasyon ve glukoz otooksidasyonu gibi diyabetin sebep olduğu metabolik anormallikleri, sürekli serbest radikal üretimine yol açarak oksidatif strese neden olmaktadır. Artan serbest radikal üretimi, poliol yolu, protein kinaz C gibi bazı ana yolakların aktivasyonuna, gelişmiş glikasyon son ürünlerinin oluşumunda artışa ve heksozsamin yolağının aşırı aktivitesine neden olmaktadır. Aynı zamanda bu yollar, tekrar serbest radikallerin üretimine yol açarak komplikasyonların patogenezinde rol oynamaktadır (Zhang vd., 2020). Bu nedenle yüksek kan şekerini düşürmek, diyabetik komplikasyon riskini azaltmak için oldukça önem arz etmektedir.

Hiperglisemiyi azaltmak amacıyla çeşitli farmasötikler geliştirilmiş olmasına rağmen, hastaların çoğunda gaz, şişkinlik, kramp ve diyare gibi gastrointestinal sistem rahatsızlıkları yan etki olarak görülmektedir. Terapötik bitkisel yaklaşımlar, geleneksel olarak diyabet ve çeşitli rahatsızlıklarda kapsamlı etkiler göstermekte olup şifalı bitkilerin kullanımı diyabet için tamamlayıcı bir tedavi olarak tercih edilmektedir (Ríos vd., 2015). $\mathrm{Bu}$ bakımdan diyabet tedavisi ve yönetiminde nutrasötik olarak tıbbi bitkilerin uygun dozlarda ve bilinçli kullanımları yan etki bakımında daha avantajlı olabilmektedir. Tibbi bitkiler, çeşitli hastalıklara karşı koruyucu etki gösteren fenolik asitler ve flavonoidler gibi bazı biyoaktif fitokimyasal bileşiklere sahiptir. Ayrıca tıbbi ve yabani yenilebilir bitkiler, antioksidan kapasitenin arttırlarak hem serbest radikallerin azaltılmasina hem de poliol yolu, protein kinaz $\mathrm{C}$ ve heksozsamin yolaklarin aktivasyonunun engellenmesine yardımcı olabilecek doğal çareler sunabilir (Ayepola vd., 2014; Milella vd., 2014). Ayrıca bu bitkiler, önemli ölçüde kompleks karbohidratlar, mineral tuzlar, vitaminler ve polifenolik bileşikleri içermelerinden dolayı besleyici ve diyetetik değere sahip önemli besin kaynaklarıdır (Sekeroglu vd., 2006; Temiz, 2021a).

Uzun meyveli bülbül otu veya uzun hardal otu olarak bilinen Sismybrium altissimum Linnaeus, Brassicaceae ailesine ait yabani yenilebilir bir bitkidir. Bu bitki Kuzey Amerika, Asya, Avrupa, Kuzey Afrika ve Doğu Avustralya kıtalarında yayılış gösteren kozmopolit bir türdür (Mutlu ve Karakuş, 2015). S. altissimum genç yapraklarının bazı pasta çeşitlerine katılarak veya çiğ ya da pişmiş olarak tüketilebildiği rapor edilmektedir (Kargıŏlu vd., 2010; Şenkardeş \& Tuzlac1, 2016). Yoğun baharatlı yapısından dolayı Sismybrium türlerinin kökleri yemeklerde çeşni olarak kullanılmaktadır. Yapraklar vasabi sosu yapılacak kadar baharatlıdır, ancak daha çok salatalara karıştırılarak çĭg olarak tüketilmektedir (Christopher, 2017). Toprak üstü kısımlarının ve yapraklarının da haşlanıp soğan ve sumak ile pişirilerek tüketildiği belirtilmiş̧ir (Yeşil \& İnal, 2019). S. altissimum çiçek ve yapraklarının geleneksel olarak kanama durdurucu, ateş için tonik ve anti-skorbüt olarak kullanıldığ1 bildirilmiştir (Mehrnia vd., 2021). Ek olarak bazı çalışmalarda, Sisymbrium'un diğer türleri hakkında da çeşitli farmakolojik etkiler rapor edilmiştir. $S$. irio'un halk hekimliğinde iltihap ve romatizma tedavisinde kullanılmasının yanı sıra öksürüğ̈̈ kesmek, karaciğer ve dalağı detoksifiye etmek, şişlikleri azaltmak ve yaraları temizlemek amacıyla da kullanıldığ1 bildirilmiştir (Hawash vd., 2019; Nengroo \& Rauf, 2019). Oldukça keskin bir tadı olan S. officinale bitkisinin tamamı, genellikle boğaz ağrısının, soğuk algınlı̆̆ 1 ve astımın tedavisinde, ayrıca balgam söktürücü olarak kullanılmaktadır. $\mathrm{Bu}$ tedavi etkisinden dolay1 ayrıca "şarkıcının bitkisi (singer's plant)" olarak tanımlanmaktadır (Rahman vd., 2018). Aynı çalışmada, $S$. orientale tohumlarının balgam söktürücü, ateş için tonik ve bronşit tedavisinde kullanıldığg ifade edilmiştir. Bu tohumların ayrıca dizanteri, bağırsak kurdunu düşürme ve suçiçeği tedavisinde de kullanıldığı belirtilmiştir. Bütün haldeki bitki ise dekoksiyon yapılarak idrar söktürücü olarak, bağırsak kurdunu düşürme ve ağrısız ülserlerin tedavisinde kullanılmaktadır (Rahman vd., 2018). S. erysimoides'e ait tüm bitki kısımlarının bronşiti tedavi etme ve iltihabı önleyici etkiye sahip olduğu rapor edilmiştir (Rahman vd., 2018).

Yapılan literatür taramasında, S. altissimum'a ait bugüne kadar antioksidan ve antidiyabetik özelliklerini belirlemeye yönelik herhangi bir araştırmaya rastlanılmamış olup, S. altissimum ile ilgili çok sınırlı deneysel çalışma bildirilmiştir. 
Hem S. altissimum hem de Sisymbrium'un farklı türlerinin geleneksel olarak tüketiminin yaygın olduğu ve çok çeşitli etnofarmakolojik özellikleri olduğu literatürde belirtilmiştir. Bu etkiler arasında S. altissimum bitkisinin antidiyabetik ve antioksidan özelliklerinin olabileceği varsayımıyla bu çalışma planlanmıştır. $\mathrm{Bu}$ çalışma da $S$. altissimum yaprak ekstraktının polifenolik profili, antidiyabetik etkisi ve antioksidan kapasitesini ortaya koymak ve bu sayede etnofarmakolojik değerlendirilmesi amaçlanmıştır.

\section{Materyal ve metot}

\section{Material and method}

\subsection{Kimyasallar}

\subsection{Chemicals}

Gallik asit (27645, saflık $\geq \% 99)$, protokateşuik asit (37580, saflık $\geq \% 97$ ), kateşin (C1251, saflık $\geq \% 98$ ), klorojenik asit (C3878, saflık $\geq \% 95$ ), kaffeik asit (C0625, saflık $\geq 98)$, şiringik asit (S6881, saflık $\geq \% 95$ ), kuersetin (Q4951, saflık $\geq \% 95), \quad p$-kumarik asit (C9008, saflık $\geq \% 98)$, ferulik asit (128708, saflık $\geq \% 99$ ), rutin (R5143, saflık $\geq \% 94), o$-kumarik asit (H22809, saflik $\geq \% 97)$, alüminyum klorid (294713, saflık $\geq \% 99.99)$, DPPH (D9132), ABTS (10102946001), $\alpha$-amilaz (A3176), $\alpha$-glukozidaz (G5003), dinitrosalisilik asit (D0550) ve 4-nitrofenil $\alpha$-Dglukopiranosid (487506) Sigma (St. Louis, MO, ABD) firmasından temin edilmiştir. Etanol, metanol, asetik asit ve asetonitril Merck (Darmstadt, Almanya) firmasindan temin edilmiştir. Akarboz (Glucobay® ${ }^{\circledR}$, Türkiye) yerel bir eczaneden temin edilmiştir. Çalışmada kullanılan diğer tüm kimyasallar ve reaktifler HPLC ve/veya analitik saflıktadır.

\subsection{Bitki materyali ve ekstraksiyon}

\subsection{Plant material and extraction}

Sismybrium altissimum bitkisi 2020 yılının Mayıs ayında Karaman iline bağlı Pınarbaşı mevkiinden toplanmıştır. Daha sonra bitkiler hemen laboratuvara getirilerek yabancı maddelerden uzaklaştırıldı ve bitki bir uzman tarafindan teşhis edilerek bir örneği Karamanoğlu Mehmetbey Üniversitesi Teknik Bilimler Meslek Yüksek Okulu bitkisel üretim laboratuvarına konuldu. Bitkiler ortalama $18^{\circ} \mathrm{C}$ ve $\% 41$ nem seviyesinde açık havada ve gölgede yaklaşık 4 gün'de kurutuldu. Kurutulmuş yapraklar laboratuvar mikseriyle parçalandı ve manyetik karıştırıcı (Wisd WiseStir MSH-20D) ile sürekli karıştııılarak 3 saat boyunca $50^{\circ} \mathrm{C}$ 'de $\% 80$ etanol ile iki kez ekstrakte edildi (Temiz, 2021a; Temiz, 2021b). Süre sonunda ekstrakt cendere bezi ile süzüldükten sonra, $22 \mu \mathrm{m}$ PTFE ile filtre edildi. S. altissimum ekstraktı (SAE) sonraki analizlere kadar amber şişelerde $-20^{\circ} \mathrm{C}^{\prime} \mathrm{de}$ muhafaza edildi.

\subsection{Fenolik profil analizi}

\subsection{Phenolic profile analysis}

Örneklerin fenolik profilleri, HPLC sistemi (Agilent Technologies 1260 Infinity, ABD) kullanılarak daha önce açıklandığı gibi (Temiz, 2021b) belirlendi. Fenolik bileşiklerin tespiti, $25^{\circ} \mathrm{C}$ 'de gradient çözücü sistemi aracılığıyla bir Inertsil ODS-3 C18 (250 x $4.6 \mathrm{~mm}, 5 \mu \mathrm{m})$ kolon kullanılarak yapıldı. Elüsyon, su/asetik asit $(98: 2$ $\mathrm{v} / \mathrm{v})(\mathrm{A})$ ve asetonitril/su/asetik asit (50:49.5:0.5 $\mathrm{v} / \mathrm{v} / \mathrm{v}$ ) (B) mobil fazlar kullanılarak gerçekleştirildi. Gradient program 10 . dakika $\% 85$ A, 30. dakika $\% 80 \mathrm{~A}, 60$. dakika $\% 55$ A olacak şekilde ayarlandı. Diyot dizisi detektörü (DAD) 254, 280 ve $320 \mathrm{~nm}$ dalga boylarına ayarlanarak kayıt yapıldı. Her bir bileşiğin tanımlanması, alıkonma sürelerine ve harici standartlarla karşılaştırılarak spektral eşleşmeye dayandırıldı.

\subsection{Toplam fenolik ve toplam flavonoid madde tayini}

2.4. Determination of total phenolic and total flavonoid content

SAE'deki toplam fenolik madde miktarı, standart olarak gallik asit kullanılarak modifiye FolinCiocalteu reaktif yöntemi (Singleton vd., 1999) ile belirlendi. Toplam fenolik madde miktarı, mg gallik asit eşdeğeri $100 \mathrm{~g}^{-1}$ kuru madde (mg $\mathrm{GAE} / 100 \mathrm{~g} \mathrm{~km}$ ) olarak hesaplandı. Örneklerin toplam flavonoid madde miktarı, standart olarak kuersetin kullanılarak $\mathrm{AlCl}_{3}$ yöntemi (Zhishen vd., 1999) ile ölçüldü. Sonuçlar mg kuersetin eşdeğeri $100 \mathrm{~g}^{-1}$ kuru madde (mg QE/100 $\mathrm{g} \mathrm{km}$ ) olarak hesapland.

\subsection{DPPH radikal temizleme aktivitesi}

\subsection{DPPH radical scavenging activity}

DPPH radikal temizleme aktivitesi, Pyo vd. (2004) tarafından belirtilen yöntemde baz1 modifikasyonlar yapılarak gerçekleştirildi. Kısaca, $100 \mu \mathrm{L}$ farklı konsantrasyonlarda seyreltilmiş SAE $(1-50 \mathrm{mg} / \mathrm{mL})$ ve $3.90 \mathrm{~mL}$ metanolik $\mathrm{DPPH}^{\circ}\left(6 \times 10^{-}\right.$ 5 M) çözeltisi farklı ependorf tüpler içinde karıştırıldı ve vortekslendi. Tüpler karanlıkta ve oda sıcaklığında 60 dakika boyunca inkübe edildi. Daha sonra 517 nm'de (Shimadzu UV-3600, Kyoto, Japonya) metanole karşı absorbansları ölçüldü. Örneklerin DPPH radikal temizleme aktivitesi, troloks $(0.01-0.5 \mathrm{mg} / \mathrm{mL}) \quad$ standart 
grafiğine göre hesaplanıp ifade edildi. Ayrıca radikallerin \%50'sini inhibe etmek için gereken ekstraktın $(\mathrm{mg} / \mathrm{mL})$ konsantrasyonu olan $\mathrm{SC}_{50}$ değeri de ifade edildi.

\subsection{ABTS radikal temizleme aktivitesi}

\subsection{ABTS radical scavenging activity}

ABTS $(7 \mathrm{mM})$, karanlıkta ve oda sicaklığında ABTS radikal katyonu $\left(\mathrm{ABTS}^{\circ+}\right)$ oluşturmak için potasyum persülfat $(2.45 \mathrm{mM})$ içinde $12-16$ saat süre boyunca inkübe edildi. Süre sonunda analiz için $\mathrm{ABTS}^{\circ+}$ distile su ile seyreltilerek $734 \mathrm{~nm}$ dalga boyunda $0.70 \pm 0.02$ absorbans1 elde edilerek kullanıma hazır hale getirildi (Re vd., 1999). Analiz kısaca, $20 \mu \mathrm{L}$ farklı konsantrasyonlarda seyreltilmiş SAE $(1-50 \mathrm{mg} / \mathrm{mL})$ ve $1980 \mu \mathrm{L}$ ABTS $^{*+}$ çözeltisi farklı tüplere eklendi ve vortekslendi. Daha sonra tüpler 6 dakika boyunca oda sicaklığında ve karanlıkta birakıldı. Süre sonunda absorbanslar $734 \mathrm{~nm}$ dalga boyunda ölçüldü. Ekstraktın ABTS $^{++}$inhibe etme kabiliyeti troloks $(0.01-0.5 \mathrm{mg} / \mathrm{mL})$ standardına göre grafik oluşturularak hesaplanıp ifade edildi. Ayrıca radikallerin \%50'sini inhibe etmek için gereken ekstraktın $(\mathrm{mg} / \mathrm{mL})$ konsantrasyonu olan $\mathrm{SC}_{50}$ değeri de ifade edildi.

\section{7. $\alpha$-amilaz ve $\alpha$-glukozidaz inhibisyon aktivite tayini}

2.7. Determination of $\alpha$-amylase and $\alpha$-glucosidase inhibition activity

SAE'nin $\alpha$-amilaz inhibisyon aktivitesi, Kim vd., (2005) tarafından bildirilen yöntemde küçük modifikasyonlar yapilarak belirlendi. Fosfat tamponu içinde $(0.02 \mathrm{M}, \mathrm{pH}=6.9)$ toplam $250 \mu \mathrm{L}$ $\alpha$-amilaz $(0.05 \mathrm{U} / \mathrm{mL})$, farkl1 konsantrasyonlarda seyreltilmiş $(1-50 \mathrm{mg} / \mathrm{mL}) 200 \mu \mathrm{L}$ ekstrakt ile farklı tüplerde karıştırıldı ve $37^{\circ} \mathrm{C}^{\prime}$ de 10 dakika inkübe edildi. Daha sonra substrat olarak nişasta çözeltisinden (\%1) $250 \mu \mathrm{L}$ ilave edilerek $37^{\circ} \mathrm{C}$ 'de 15 dakika inkübe edildi. Reaksiyon $500 \mu \mathrm{L} \% 1$ dinitrosalisilik asit ile durdurulduktan sonra, tüpler kaynar su içinde 10 dakika bekletildi. Tüpler soğutulduktan sonra karışım $5 \mathrm{~mL}$ distile su ile seyreltildi. Karışımın absorbansı $540 \mathrm{~nm}$ dalga boyunda ölçüldü. Aynı işlemler standart madde olarak kullanılan akarboz içinde tekrarlandı. Ekstraktın $\alpha$-amilaz inhibisyon aktivitesi grafiksel olarak hesaplanıp $\mathrm{mg} / \mathrm{mL}$ cinsinden $\mathrm{IC}_{50}$ olarak ifade edildi.

$\alpha$-glukozidaz inhibisyon aktivitesinin belirlenmesinde, fosfat tamponu (0.1 M, pH=6.8) içindeki $60 \mu \mathrm{L} 1 \mathrm{U} / \mathrm{mL} \alpha$-glukozidaz, $120 \mu \mathrm{L}$ farklı konsantrasyonlarda seyreltilmiş SAE (1-50 $\mathrm{mg} / \mathrm{mL}$ ) ile farklı tüplerde karıştırıldı ve $37^{\circ} \mathrm{C}$ de 10 dakika inkübe edildi. Daha sonra $120 \mu \mathrm{L} 4-$ nitrofenil $\alpha$-D-glukopiranosid $(5 \mathrm{mM})$ substrat olarak eklendi ve tüpler 15 dakika $37^{\circ} \mathrm{C}^{\prime}$ de tutuldu. Reaksiyon, $300 \mu \mathrm{L} \mathrm{Na}_{2} \mathrm{CO}_{3}(0.1 \mathrm{M})$ ilave edilerek sonlandırıld1 ve absorbans, $405 \mathrm{~nm}$ dalga boyunda kaydedildi (Kim vd., 2005). Aynı işlemler standart madde olarak kullanılan akarboz içinde tekrarlandı. Ekstraktın $\alpha$-glukozidaz inhibisyon aktivitesi, grafiksel olarak hesaplanıp $\mathrm{mg} / \mathrm{mL}$ cinsinden $\mathrm{IC}_{50}$ olarak ifade edildi. Çalışmadaki tüm ölçümler aynı koşullarda ve aynı gün üç paralel ile yapıldı.

\section{Bulgular ve tartışma \\ 3. Results and discussion}

\subsection{S. altissimum ekstraktının fenolik profili}

3.1. Phenolic profile of S. altissimum extract

S. altissimum yaprak ekstraktında bulunan fenolik bileşenlerin miktarı Tablo 1'de, HPLC kromatogramı ise Şekil 1b'de sunulmuştur. Rutin, SAE'de en çok bulunan fenolik bileşen olarak tespit edildi. Ayrıca kuersetin ve protokateşuik asit ise diğer baskın fenolik bileşikler olarak belirlendi. Al-Taie vd., (2018) tarafindan Sisymbrium officinale yapraklarında $p$-kumarik asit ve protokateşuik asidin, Sisymbrium irio yapraklarında sinnamik asit, gentisik asit, $p$ kumarik asit ve protokateşuik asidin, Sisymbrium septulatum yapraklarında ise $p$-kumarik asit, sinnamik asit, protokateşuik asidin en fazla bulunan fenolik bileşikler olduğu rapor edilmiştir. $S$. officinale toprak üstü kısımlarının diklorometan fraksiyonunda ferulik asidin en çok bulunan fenolik bileşen olduğu belirtilmiştir (Amodeo vd., 2019). Aynı çalışmada, etil asetat fraksiyonunda yüksek performans ince tabaka kromatografisi ile klorojenik asit tanımlanmıştır (Amodeo vd., 2019). Başka bir çalışmada, S. irio toprak üstü kısımlarından apigenin, luteolin-7-O-glukozit ve kamferol (Al-Jaber, 2011), tüm bitkiden de apigenin ve naringenin (Al-Qudah \& Abu Zarga, 2009) fenolik bileşikleri izole edilmiştir. $\mathrm{Bu}$ sonuçlarda, Sisymbrium türleriyle daha önce yapılan çalışmaların $S$. altissimum yaprağında bulunan fenolik bileşiklerle benzer olduğuna ancak saptanan fenolik bileşenlerin oran ve çeşit olarak farklılık gösterebileceği belirlenmiştir. Fenolik bileşikler benzer bitki cinslerinde ve/veya türlerinde bile farklı oran ve çeşitte bulunabilir. Bunun sebebi bitkinin iklimsel faktörler, su, güneş 1şığı, rakım, toprak özellikleri gibi büyüme koşullarına ve/veya vejatasyon periyodu gibi pek çok faktöre bağlı olarak farklı oran ve miktarlarda fenolik bileşiklerin biyosentezine bağlıdır (Chepel vd., 2020). Ayrıca bitkiler farklı büyüme 
evrelerinde çeşitli fenolik bileşikleri üretebilir ve bunları farklı amaçlar için bitkinin diğer kısımlarında biriktirebilirler (Feduraev vd., 2019). Kullanılan çözücü polaritesinden dolayı da ekstrakte edilen fenolik bileşen çeşitleri ve miktarları bu farklılığa yol açmış olabilir (Temiz \& Temur, 2017). Diğer taraftan Şekil 1b'de tespit edilen 37-40. dakikalar arasında $(37.707,38.681$ ve $39.300 \mathrm{dk}$.) gelen tanımlanamayan piklerin muhtemelen başka fenolik bileşikler ve/veya glukosinolatlara ait olabileceği düşünülmektedir.
Glukosinolatlar da tıpkı fenolik bileşikler gibi polar moleküllerdir ve fenoliklerin ekstraksiyonu ile birlikte ekstrakta bulunabilirler. Brassicaceae ailesi glukosinolatlar bakımından zengin bir içeriğe sahiptir (Borgonovo vd., 2019). S. officinale yaprak ve çiçeklerinden sinigrin, izopropil izotiyosiyanat ve 2-bütil izotiyosiyanat izole edilmiştir (Borgonovo vd., 2019). Bainard vd., (2009)'de $S$. loeselii kök ve sürgün ekstraklarında başlıca iki glukosinolat olan izopropil ve sec-bütil glukosinolatları tespit etmişlerdir.

Tablo 1. Sisymbrium altissimum yaprak ekstraktının fenolik bileşim miktarı (mg/kg km)

Table 1. The amount of phenolics compounds of Sisymbrium altissimum leaf extract

\begin{tabular}{|c|c|c|c|c|c|c|c|c|c|c|c|}
\hline Örnek & GA & PCA & Cath & ChA & $\mathrm{CA}$ & SyA & Que & $p$ Cou & FA & $\mathrm{Ru}$ & $o \mathrm{Cou}$ \\
\hline SAE & n.d & 245 & n.d & $104.6 \pm 0.7$ & $55.6 \pm 0.2$ & $33.04 \pm 0.2$ & $348.6 \pm 1.8$ & $74.29 \pm 0.2$ & $48.3 \pm 0.1$ & $366.1 \pm 1.4$ & $66.2 \pm 0.4$ \\
\hline
\end{tabular}

GA: gallik asit, PCA: protokateşuik asit, Cath: kateşin, ChA: klorojenik asit, CA: kaffeik asit, SyA: şiringik asit, Que: kuersetin, $p$ Cou: $p$-kumarik asit, FA: ferulik asit, Ru: rutin, $o$ Cou: $o$-kumarik asit, n.d: tespit edilemedi, SAE: Sisymbrium altissimum yaprak ekstraktı, veriler ortalama \pm standart sapmayı ifade eder, $n=3$

GA: gallic acid, PCA: protocatechuic acid, Cath: catechin, ChA: chlorogenic acid, CA: caffeic acid, SyA: syringic acid, Que: quercetin, pCou: pcoumaric acid, FA: ferulic acid, RuO: rutin, oCou: o-coumaric acid, n.d: not determined, SAE: Sisymbrium altissimum leaf extract, data shows mean \pm standard deviation, $n=3$

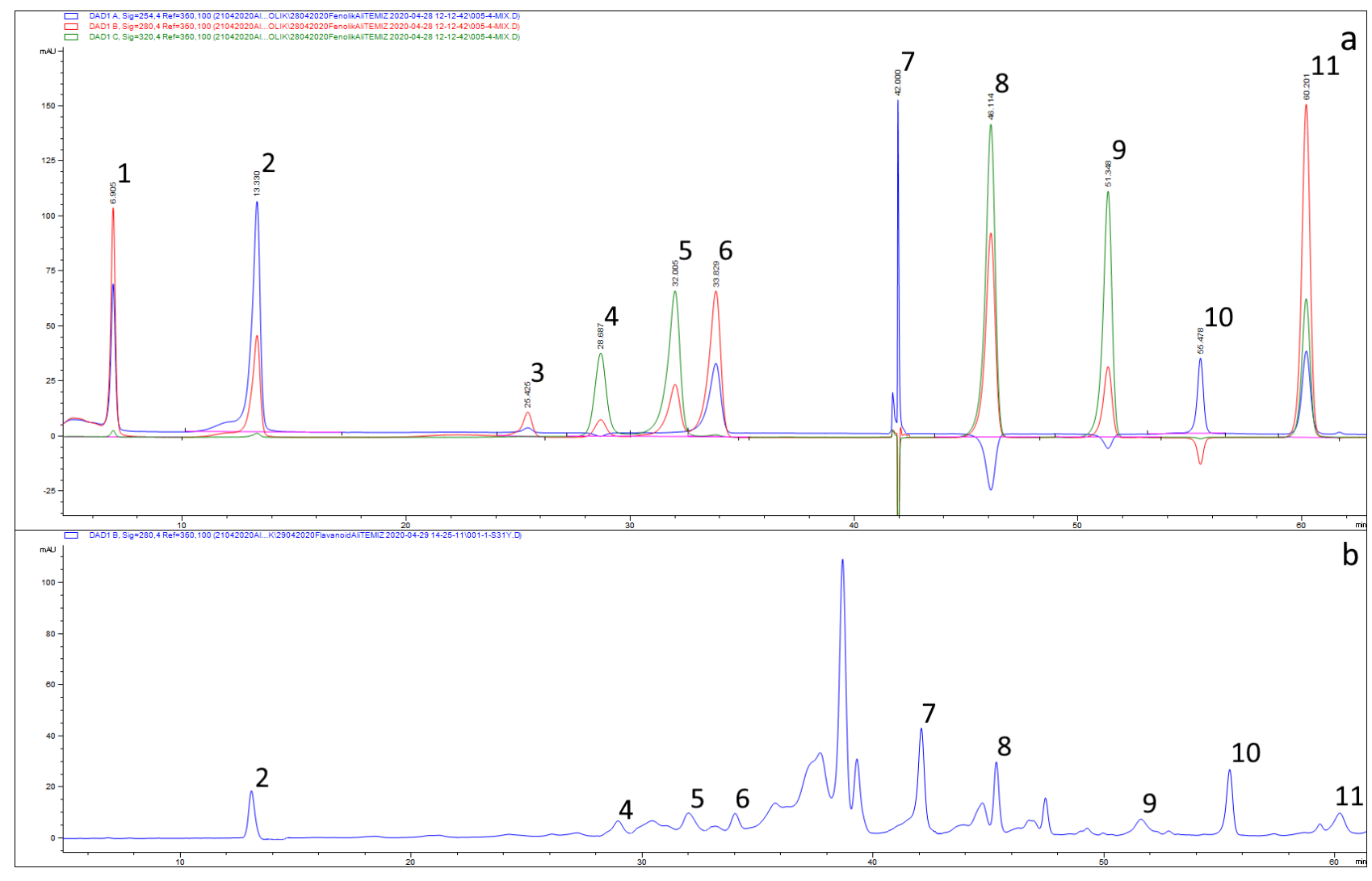

Şekil 1. Standartların 254, 280 ve $320 \mathrm{~nm}$ dalga boylarının çakıştırılmış HPLC kromatogramları (a) ve Sisymbrium altissimum yaprak ekstraktının $280 \mathrm{~nm}$ dalga boyunda HPLC kromatogramı (b). 1: gallik asit, 2: protokateşuik asit, 3: kateşin, 4: klorojenik asit, 5: kafeik asit, 6: şiringik asit, 7: kuersetin, 8: p-kumarik asit, 9: ferulik asit, 10: rutin, 11: $o$-kumarik asit.

Figure 1. HPLC chromatograms of: the standards mixture overlay of all wavelengths $(254,280$, and 320 $\mathrm{nm})($ a) and Sisymbrium altissimum leaf extract at $280 \mathrm{~nm}$ wavelength (b). 1: gallic acid, 2: protocatechuic acid, 3: catechin, 4: chlorogenic acid, 5: caffeic acid, 6: syringic acid, 7: quercetin, 8: p-coumaric acid, 9: ferulic acid, 10: rutin, 11: o-coumaric acid. 


\subsection{S. altissimum ekstraktının toplam fenolik ve flavonoid madde miktarı \\ 3.2. The amount of total phenolics and flavonoid content of $S$. altissimum extract}

Fenolik maddeler; antioksidan, antidiyabetik, antimikrobiyal, antihiperlipidemik, antikarsinojenik gibi çok çeşitli farmakolojik etkilere sahiptirler. Bu etkiler genellikle fenolik bileşiklerin fonksiyonel yan gruplarında bulunan $\mathrm{OH}$ grupları sayesinde elektron ve hidrojen transferine dayanmaktadır (Ghasemzadeh \& Ghasemzadeh, 2011). SAE'ye ait toplam fenolik madde ve toplam flavonoid madde miktarları Şekil 2'de gösterilmiştir. Mevcut çalışmada, SAE'nin toplam fenolik madde miktarı $917 \pm 71 \mathrm{mg}$ $\mathrm{GAE} / 100 \mathrm{~g} \mathrm{~km}$ ve toplam flavonoid madde miktarı ise $1091 \pm 54 \mathrm{mg} Q \mathrm{QE} / 100 \mathrm{~g} \mathrm{~km}$ olarak tespit edilmiştir. Daha önce yapılan bir çalışmada $S$. officinale toprak üstü kısımlarının metanolik maserasyon ekstraktında toplam fenolik madde ve toplam flavonoid madde sonuçları sirasıyla $8.1 \pm 0.1$ $\mathrm{mg}$ klorojenik asit eşdeğeri (KAE)/g km ve $0.50 \pm 0.01 \mathrm{mg} \mathrm{QE} / \mathrm{g} \mathrm{km}$ olarak belirlenmiştir (Amodeo vd., 2019). Bir diğer çalışmada $S$. officinale toprak üstü kısımların sulu ekstraktının toplam fenolik madde miktarları 28.1 $\mu \mathrm{g} \mathrm{KAE} / \mathrm{mg}$ $\mathrm{km}$ ve toplam flavonoid madde miktarı da $0.12 \mu \mathrm{g}$ QE/mg km olarak bulunmuştur (Di Sotto vd., 2016). Ayrıca aynı çalışmada $S$. officinale toprak üstü kısımlarının sulu ekstraktlarından hazırlanan etil asetat ve bütanol fraksiyonlarının toplam fenolik madde miktarları sirasıly 724 ve $164 \mu \mathrm{g}$ $\mathrm{KAE} / \mathrm{mg} \mathrm{km}$; toplam flavonoid madde miktarı ise 3.10 ve $3.70 \mu \mathrm{g} Q \mathrm{QE} / \mathrm{mg} \mathrm{km}$ olarak tespit edilmiştir (Di Sotto vd., 2016). Başka bir Sisymbirium türü olan S. irio parankima hücre kültürü üzerinde yapılan bir çalışmada Murashige ve Skoog besi yeri ortamında yetiştirilen kallusların metanolik ekstraktlarının toplam fenolik madde miktarı 0.11 $\mathrm{mg} \mathrm{GAE} / \mathrm{g} \mathrm{km}$ ve toplam flavonoid madde miktarı $0.13 \mathrm{mg}$ Rutin eşdeğeri $/ \mathrm{g} \mathrm{km}$ olarak rapor edilmiştir (Amin vd., 2009). Mevcut çalışmadaki toplam fenolik madde miktarı literatür ile uyumlu hatta bazı çalışma sonuçlarına göre yüksek olmakla birlikte, toplam flavonoid madde miktarı literatüre göre dikkat çekici şekilde daha yüksek bulunmuştur. $\mathrm{Bu}$ durumun sebebinin tür farklılı̆̆ının yanı sira yaprakla birlikte kullanılan gövde kısmında daha az flavonoid olabileceğinden kaynaklandığ 1 düşünülmektedir. Diğer taraftan Hailu vd. (2021) yakın zamanda yaptıkları bir çalışmada, S. irio tohumlarını $n$-hekzan, kloroform, etil asetat ve metanol ile arka arkaya ekstrakte etmişlerdir. S. irio ekstraklarında toplam fenolik madde içeriği 7.8 ile $55.3 \mu \mathrm{g}$ GAE/mg kuru ekstrakt arasında olduğu rapor edilmiştir. Ayrıca $S$. irio ekstraklarında toplam flavonoid madde içeriğinin de 8.958 ile $13.266 \mu \mathrm{g}$ QE/mg kuru ekstrakt arasında olduğu belirtilmiştir. Elde ettikleri sonuçlara göre toplam fenolik ve flavonoid madde içeriğinin en yüksek metanolik ekstrakta olduğu ifade edilmiştir (Hailu vd., 2021). Her ne kadar bitki türleri farklı olsa da benzer cinsler arasında mevcut çalışmaya göre çok farklı toplam fenolik ve toplam flavonoid madde sonuçları elde edilmiştir. Bunun nedeni, belirtilen çalışmalarda tercih edilen çözücü seçimi, ekstraksiyon işlem ve süreçleri, konsantre işlemleri, fraksiyonlama işlemleri, tercih edilen eşdeğer fenolik bileşik, ve/veya kullanılan bitki kısmının farklı olmasından kaynaklandığı düşünülmektedir.

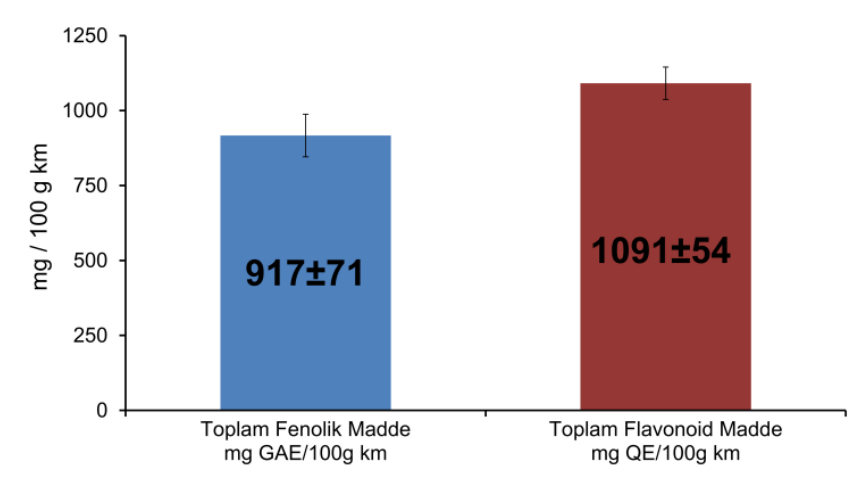

Şekil 2. Sisymbrium altissimum yaprak ekstraktının toplam fenolik madde ve toplam flavonoid madde miktarı. GAE: gallik asit eşdeğeri, QE: kuersetin eşdeğeri, veriler ortalama \pm standart sapmay 1 ifade eder, $n=3$

Figure 2. The amount of total phenolics and flavonoid content of $S$. altissimum leaf extract. GAE: gallic acid equivalent, QE: quercetin equivalent, data shows mean \pm standard deviation, $n=3$

\subsection{S. altissimum ekstraktının serbest radikal temizleme aktivitesi}

3.3. Free radical scavenging activity of $S$. altissimum

DPPH ve ABTS antioksidan tayin yöntemleri, antioksidan kapasite analizlerinde hem lipofilik hem de hidrofilik antioksidanların hidrojen veya elektron transferi ile serbest radikalleri temizleme kabiliyetini hızlı bir şekilde değerlendirmek amaciyla yaygın olarak kullanılmaktadır. Bu analizler, polifenollerin lipid peroksil radikalleri ile nispi antioksidan ve koruyucu aktivitelerin tespitinde iyi sonuçlar vermektedir (Niki, 2010). SAE'nin DPPH yönteminde $\mathrm{IC}_{50}$ değeri $80.21 \pm 3.62 \mathrm{mg}$ TE$/ \mathrm{g}$ ekstrakt olarak; ABTS yönteminde ise $\mathrm{IC}_{50}$ değeri $94.52 \pm 2.46 \mathrm{mg} \mathrm{TE} / \mathrm{g}$ ekstrakt olarak bulunmuştur (Tablo 2). Aynı zamanda SAE'nin $\mathrm{SC}_{50}$ değeri de $\mathrm{DPPH}$ için 
$22.45 \pm 1.46 \mathrm{mg} / \mathrm{mL}$ ekstrakt, ABTS için $25.11 \pm 1.24 \mathrm{mg} / \mathrm{mL}$ ekstrakt olarak tespit edilmiştir (Tablo 2). Temel olarak, daha düşük $\mathrm{IC}_{50}$ değeri, daha yüksek inhibisyon aktivitesini ifade eder. Hazırlanmış olan ekstrakt birbirinin katı olan farklı konsanstrasyonlarda dilüe edilmiştir. $\mathrm{Bu}$ dilüsyonlar 1-50 $\mathrm{mg} / \mathrm{mL}$ olacak şekilde ayarlanmıştır. $\mathrm{Bu}$ aralıkların seçilme sebebi; analizlerde hesaplanan sonuçların sıfirdan küçük, 100 'den büyük olmamasını sağlamaktır. $\mathrm{Bu}$ aralıklardaki dilüsyonlar ile çalışılarak yarı maksimum inhibitör konsantrasyonu olan $\mathrm{IC}_{50}$ ve $\mathrm{SC}_{50}$ değerleri hesaplanmıştır. Yakın zamanda yapılan bir çalışmada, $S$. officinale toprak üstü kısımlarının metanolik ekstraktının DPPH $\mathrm{IC}_{50}$ değeri $143 \mu \mathrm{g} / \mathrm{mL}$ olarak belirlenmiştir (Amodeo vd., 2019). Başka bir çalışmada, S. irio toprak üstü kısımlarının etanolik ekstraktının DPPH inhibisyon değeri $10 \mathrm{mg} / \mathrm{mL}$ konsantrasyonda
\%55.7 olarak tespit edilmiştir (El-Meligy vd., 2017). Bir diğer çalışmada ise Hailu vd. (2021), $S$. irio tohumlarının farklı çözücü ekstraktlarının DPPH aktivitesinin $1 \mathrm{mg} / \mathrm{mL}$ konsantrasyonda $\% 22.3$ ile $\% 79.9$ arasında olduğunu rapor etmişlerdir. Aynı çalışmada ABTS aktivitesinin $\% 43$ ile \%94.3 aralığına sahip olduğu ifade edilmiştir (Hailu vd., 2021). Diğer taraftan S. irio tohumunun $200 \mu \mathrm{g} / \mathrm{mL}$ petrol eteri ekstraktının DPPH inhibisyon aktivitesinin (\%82) BHT (\%87) ile karşılaştırıldığında birbirlerine çok yakın değerlere sahip olduğu belirlenmiştir (Nengroo \& Rauf, 2019). Mevcut çalışma literatür ile karşılaştırıldığında antioksidan kapasite tayinlerinde, radikal temizleme aktiviteleri arasında çok farklı sonuçların olduğu görülmüsşür. $\mathrm{Bu}$ farkların muhtemelen tercih edilen çözücü, bitki kısmı, analiz metodu ve sonuçların ifade edilme birimine göre değiştiği düşünülmektedir.

Tablo 2. Sisymbrium altissimum yaprak ekstraktının $\mathrm{DPPH}$ ve $\mathrm{ABTS} \mathrm{IC}_{50}$ ve $\mathrm{SC}_{50}$ değerleri Table 2. The value of DPPH and ABTS IC $C_{50}$ and $S C_{50}$ of Sisymbrium altissimum leaf extract

\begin{tabular}{lcccc}
\hline Örnek & $\begin{array}{c}\text { DPPH } \\
(\mathbf{m g} \text { TE/g ekstrakt) }\end{array}$ & $\begin{array}{c}\text { ABTS } \\
(\mathbf{m g} \text { TE/g ekstrakt) }\end{array}$ & $\begin{array}{c}\text { DPPH } \\
\left(\mathbf{S C}_{\mathbf{5 0}} \mathbf{~ m g / m L}\right)\end{array}$ & $\begin{array}{c}\text { ABTS } \\
\left(\mathbf{S C}_{\mathbf{5 0}} \mathbf{~ m g} / \mathbf{m L}\right)\end{array}$ \\
\hline SAE & $80.21 \pm 3.62$ & $94.52 \pm 2.46$ & $22.45 \pm 1.46$ & $25.11 \pm 1.24$ \\
Troloks & & & $0.23 \pm 0.004$ & $0.21 \pm 0.003$ \\
\hline
\end{tabular}

TE: troloks eşdeğeri, SAE: Sisymbrium altissimum yaprak ekstrakt1, veriler ortalama \pm standart sapmayı ifade eder, $n=3$

TE: trolox equivalent, SAE: Sisymbrium altissimum leaf extract, data shows mean \pm standard deviation, $n=3$

\subsection{S. altissimum ekstraktının $\alpha$-amilaz ve $\alpha$ - glukozidaz inhibisyon aktivitesi}

3.4. $\alpha$-amylase and $\alpha$-glucosidase inhibition activity of $S$. altissimum extract

Diyabet tedavilerinde yemek sonrası kan glukoz düzeyinin azaltılması, genellikle diğer tedavi yöntemleriyle kombine olarak tercih edilmektedir. $\mathrm{Bu}$ amaç doğrultusunda akarboz gibi ticari ilaçlar nişasta ve glikojen gibi kompleks karbohidratların bağırsak yolunda hidrolizinin yavaşlatılması amaciyla enzimlerin inhibisyonunda kullanılmaktadır. Ancak hastalar genellikle bu gibi ilaçların çeşitli yan etkilerinden muzdariptirler. $\mathrm{Bu}$ şikâyetlerden dolayı ve ayrıca geleneksel tamamlayıcı bir tedavi olduğu düşüncesiyle tıbbi bitki temelli doğal farmasötiklere yönelmektedirler (Temiz, 2021a). Fenolik bileşikler doğal $\alpha$-amilaz ve $\alpha$-glukozidaz inhibitörü özellikleriyle karbohidrat sindirim süresini geciktirip/uzatarak glukoz emilim hızında azalmaya neden olurlar ve sonuç olarak yemek sonrası kan glukoz artışını azaltırlar. Mevcut çalışmada S. altissimum yaprak ekstraktının $\alpha$-amilaz ve $\alpha$-glukozidaz inhibisyon değerleri akarboz ile kıyaslandığında yaklaşı 7 kat daha az etkin bulunmuştur (Tablo 3). Daha önce $S$. irio yapraklarının hidrofilik ve lipofilik fraksiyonlarının $\alpha$-amilaz inhibisyon $\mathrm{IC}_{50}$ değerleri sirasiyla, $180 \mathrm{ve} 7.72 \mu \mathrm{g} / \mathrm{mL}$ olarak rapor edilmiştir (Hawash vd., 2019). Aynı çalışmada pozitif kontrol akarboz için $10 \mu \mathrm{g} / \mathrm{mL}$ değeri bulunmuştur. Fraksiyonlar arasındaki farkın ekstraksiyon verimlerinden kaynaklandığı söylenebilir. Literatür bulguları mevcut çalışmadaki SAE ile göreceli olarak karşılaştırıldığında, S. irio lipofilik fraksiyonun $\alpha$-amilaz inhibisyon yeteneğinin daha etkili; hidrofilik fraksiyonun ise SAE'ye göre daha az etkili olduğu söylenebilir. Daha önce yapılan pek çok çalışmada fenolik bileşiklerin $\alpha$-amilaz ve $\alpha$-glukozidaz inhibisyon aktiviteleri arasinda doğrudan bir ilişki olduğu gösterilmiştir. In silico yapılan bir çalışmada, fenolik bileşiklerin bu inhibisyon yeteneklerinin - $\mathrm{OH}$ gruplarını $(\mathrm{H}$ verici) varlığına dayandırılmış ve enzimin aktif bölgesine olan yüksek bağlanma afinitesi yoluyla olduğu ileri sürülmüştür (Abdelli vd., 2021). Bitkilerdeki fitokimyasallar çeşitli mekanizmalar yoluyla antidiyabetik etki gösterebilirler. Bunlar arasında sindirim enzimlerinin inhibisyonu, inkretin-insülin mimetik etki, $\beta$-hücrelerinden insülin salgılanmasının uyarılması, insülin duyarlılığının iyileştirilmesi, glukozun hücrelere alımının ve biyoyararlanımının artırılması say1labilir (Yang vd., 2015; Temiz \& Temur, 2019; 
Zhang vd., 2020; Temiz, 2021a). Diğer taraftan bu etki mekanizmaları tam olarak aydınlatılamamıştır. $\mathrm{Bu}$ mekanizmalar altında yatan nedenler hem in vitro hem de in vivo koşullarda karmaşık yolaklara sahiptir. Bu nedenle, bu çalışmalar antidiyabetik etki mekanizmalarının ileride yapılacak çalışmalarla aydınlatılmasına öncülük edebilir.

Tablo 3. Sisymbrium altissimum yaprak ekstraktının $\alpha$-amilaz ve $\alpha$-glukozidaz inhibisyon $\mathrm{IC}_{50}$ değeri

Table 3. $\alpha$-amylase and $\alpha$-glucosidase inhibition $I C_{50}$ values of Sisymbrium altissimum leaf extract

\begin{tabular}{lcc}
\hline Örnekler & $\boldsymbol{\alpha}$-amilaz $(\mathbf{m g} / \mathbf{m L})$ & $\boldsymbol{\alpha}$-glukozidaz $(\mathbf{m g} / \mathbf{m L})$ \\
\hline SAE & $2.84 \pm 0.01$ & $4.46 \pm 0.10$ \\
Akarboz & $0.40 \pm 0.02$ & $0.61 \pm 0.01$
\end{tabular}

SAE: Sisymbrium altissimum yaprak ekstraktı, veriler ortalama \pm standart sapmayı ifade eder, $n=3$

SAE: Sisymbrium altissimum leaf extract, data shows mean \pm standard deviation, $n=3$

\section{Sonuçlar \\ 4. Conclusions}

Sisymbrium altissimum sahip olduğu fenolik bileşenler sayesinde iyi bir antioksidan özellik göstererek, kısmi antidiyabetik etkisi ile diyabet tedavisinde tamamlayıc1 bir rol oynayabilir. $\mathrm{Bu}$ sayede oksidan/antioksidan dengenin korunmasında ve diyabet yönetiminde potansiyel etkinliğinin yanı sıra çeşitli rahatsızlıklar için yararlı çoklu etkiler sunabilir. Ayrıca diyabet tedavisi için geleneksel fitoterapötik yaklaşımların deneysel olarak araştırılması önemli yeni bilgiler sağlayarak ileride yapılacak olan diğer çalışmalara öncü olabilir.

\section{Teşekkür}

Acknowledgement

Makalenin inceleme ve değerlendirme aşamasında yapmış oldukları katkılardan dolayı editör ve hakem/hakemlere teşekkür ederiz.

\section{Yazar katkısı}

Author contribution

$\mathrm{Bu}$ çalışmanın dizaynı, laboratuvar çalışmaları, istatistiksel hesaplamaları ve makale yazımı M.A Temiz tarafindan gerçekleştirilmiştir.

\section{Etik beyanı}

Declaration of ethical code

Bu makalenin yazarları, bu çalışmada kullanılan materyal ve yöntemlerin etik kurul izni ve / veya yasal-özel izin gerektirmediğini beyan etmektedir.

\section{Çıkar çatışması beyanı \\ Conflicts of interest}

Yazarlar herhangi bir çıkar çatışması olmadığını beyan eder.

\section{Kaynaklar \\ References}

Abdelli, I., Benariba, N., Adjdir, S., Fekhikher, Z., Daoud, I., Terki, M., Benramdane, H. \& Ghalem, S. (2021). In silico evaluation of phenolics compounds as inhibitors of $\alpha$-amylase and $\alpha$ glucosidase. Journal of Biomolecular Structure and Dynamics, 39(3), 816-822. https://doi.org/10.1080/07391102.2020.1718553

Al-Jaber, N.A. (2011). Phytochemical and biological studies of Sisymbrium irio L. growing in Saudi Arabia. Journal of Saudi Chemical Society, 15, 345-350.

https://doi.org/10.1016/j.jscs.2011.04.010

Al-Taie, G.R.I., Al-Mashea, R.A., Saddon, N. \& AlAnbari, A.K. (2018). A comparative study of the phenolic compounds of some Brassicaceae taxa by high-performance liquid chromatography (HPLC) technique. Tikrit Journal of Pure Science, $\quad 23(2), \quad 45-48$. https://doi.org/10.25130/tjps.23.2018.027

Al-Qudah, M.A. \& Abu Zarga, M.H. (2009). Chemical constituents of Sisymbrium irio L. from Jordan. Natural Product Research, 24(5), 448-456. https://doi.org/10.1080/14786410903388025

Amin, G.H., Al-Gendy, A.A., El-Ayouty, Y.M. \& Abdel-Motteleb, A. (2009). Effect of Spirulina platensis extract on growth, phenolic compounds and antioxidant activities of Sisymbrium Irio callus and cell suspension cultures. Australian Journal of Basic and Applied Sciences, 3(3), 2097-2110.

Amodeo, V., Marrelli, M., Pontieri, V., Cassano, R., Trombino, S., Conforti, F. \& Statti, G. (2019). Chenopodium album L. and Sisymbrium officinale (L.) Scop.: Phytochemical content and in vitro antioxidant and anti-inflammatory $\begin{array}{llll}\text { potential. } & \text { Plants, } & 8, & 505-519\end{array}$ https://doi.org/10.3390/plants8110505

Ayepola, O.R., Brooks, N.L. \& Oguntibeju, O.O. (2014). Antioxidant-antidiabetic agents and 
human health (Vol. 1). London: Intech Open. https://doi.org/10.5772/57282

Bainard, L.D., Brown, P.D. \& Upadhyaya, M.K. (2009). Inhibitory effect of tall hedge mustard (Sisymbrium loeselii) allelochemicals on rangeland plants and Arbuscular Mycorrhizal fungi. Weed Science, 57(4), 386-393. https://doi.org/10.1614/WS-08-151.1

Borgonovo, G., Zimbaldi, N., Guarise, M., De Nisi, P., De Petrocellis, L., Moriello, A.S. \& Bassoli, A. (2019). Isothiocyanates and glucosinolates from Sisymbrium officinale (L.) Scop. ("the Singers' Plant"): Isolation and in vitro assays on the somatosensory and pain receptor TRPA1 channel. Molecules, 24, 949-960. https://doi.org/10.3390/molecules24050949

El-Meligy, R.M., Awaad, A.S., Soliman, G.A., Kenawy, S.A. \& Alqasoumi, S.I. (2017). Prophylactic and curative anti-ulcerogenic activity and the possible mechanisms of action of some desert plants. Saudi Pharmaceutical Journal, 25, 387396. https://doi.org/10.1016/j.jsps.2016.10.008

Chepel, V., Lisun, V. \& Skrypnik, L. (2020). Changes in the content of some groups of phenolic compounds and biological activity of extracts of various parts of heather (Calluna vulgaris (L.) Hull) at different growth stages. Plants, 9(926), 1-19. https://doi.org/10.3390/plants9080926

Christopher, N. (2017). Foraging Washington: Finding, Identifying, and Preparing Edible Wild Foods (Vol. 1). Guilford: Falcon Guides.

Di Sotto, A., Di Giacomo, S., Toniolo, C., Nicoletti, M. \& Mazzanti, G. (2016). Sisymbrium officinale (L.) Scop. and its polyphenolic fractions unhibit the mutagenicity of tert-butylhydroperoxide in Escherichia coli WP2uvrAR strain. Phytotherapy Research, 30, 829-834. https://doi.org/10.1002/ptr.5588

Feduraev, P., Chupakhina, G., Maslennikov, P., Tacenko, N. \& Skrypnik, L. (2019). Variation in phenolic compounds content and antioxidant activity of different plant organs from Rumex crispus L. and Rumex obtusifolius L. at different growth stages. Antioxidants, 8(237), 1-15. https://doi.org/10.3390/antiox 8070237

Ferrier, D.R. (2017). Lippincott Illustrated Reviews: Biochemistry ( $7^{\text {th }}$ ed.). China: Wolters Kluwer.

Ghasemzadeh, A. \& Ghasemzadeh, N. (2011). Flavonoids and phenolic acids: Role and biochemical activity in plants and human. Journal of Medicinal Plants Research, 5(31), 6697-6703.

https://doi.org/10.5897/JMPR11.1404
Hailu, T., Gupta, R.K. \& Rani, A. (2021). Phytochemicals and antioxidant activity of Sisymbrium irio L. seeds. Indian Journal of Traditional Knowledge, 20(1), 26-32.

Hawash, M., Jaradat, N., Elaraj, J., Hamdan, A., Lebdeh, S.A. \& Halawa, T. (2019). Evaluation of the hypoglycemic effect of seven wild folkloric edible plants from Palestine. Journal of Complementary and Integrative Medicine, 17(1), 1-10. https://doi.org/10.1515/jcim-2019-0032

Kargığlu, M., Cenkci, S., Serteser, A., Konuk, M. \& Vural, G. (2010). Traditional uses of wild plants in the middle aegean region of Turkey. Human Ecology, 38, 429-450. https://doi.org/10.1007/s10745-010-9318-2

Kim, Y.M., Jeong, Y.K., Wang, V.W., Lee, Y. \& Rhee, H.I. (2005). Inhibitory effect of pine extract on $\alpha$ glucosidase activity and postprandial hyperglycemia. Nutrition, 21, 756-761. https://doi.org/10.1016/j.nut.2004.10.014

Mehrnia, M., Akaberi, M., Amiri, M.S., Nadaf, M. \& Emami, S.A. (2021). Ethnopharmacological studies of medicinal plants in central Zagros, Lorestan province, Iran. Journal of Ethnopharmacology, https://doi.org/10.1016/j.jep.2021.114080

Milella, L., Bader, A., De Tommasi, N., Russo, D. \& Braca, A. (2014). Antioxidant and free radicalscavenging activity of constituents from two Scorzonera species. Food Chemistry, 160, 298304.

https://doi.org/10.1016/j.foodchem.2014.03.097

Mutlu, B. \& Karakuş, Ş. (2015). A new species of Sisymbrium (Brassicaceae) from Turkey: morphological and molecular evidence. Turkish Journal of Botany, 39, 325-333. https://doi.org/10.3906/bot-1404-28

Nengroo, Z.R. \& Rauf, A. (2019). Fatty acid composition and antioxidant activities of five medicinal plants from Kashmir. Industrial Crops \& Products, $140, \quad 111596$. https://doi.org/10.1016/j.indcrop.2019.111596

Niki, E. (2010). Assessment of antioxidant capacity in vitro and in vivo. Free Radical Biology \& Medicine, 49, 503-515. https://doi.org/10.1016/j.freeradbiomed.2010.04 .016

Pyo, Y.H., Lee, T.C., Logendra, L. \& Rosen, R.T. (2004). Antioxidant activity and phenolic compounds of swiss chard (Beta vulgaris subspecies cycla) extracts. Food Chemistry, 85, 19-26. https://doi.org/10.1016/S03088146(03)00294-2 
Rahman, M., Khatun, A., Liu, L. \& Barkla, B.J. (2018). Brassicaceae Mustards: Traditional and Agronomic Uses in Australia and New Zealand. Molecules, 23, 1-18. https://doi.org/10.3390/molecules23010231

Re, R., Pellegrini, N., Proteggente, A., Pannala, A., Yang M. \& Rice-Evans, C. (1999). Antioxidant Activity Applying an Improved ABTS Radical Cation Decolorization Assay. Free Radical Biology \& Medicine, 26, 1231-1237. https://doi.org/10.1016/S0891-5849(98)00315-3

Ríos, J.L., Francini, F. \& Schinella, G.T. (2015). Natural products for the treatment of type 2 diabetes mellitus. Planta Medica, 81, 975-994. https://doi.org/10.1055/s-0035-1546131

Sekeroglu, N., Ozkutlu, F., Deveci, M., Dede, O. \& Yilmaz, N. (2006). Evaluation of some wild plants aspect of their nutritional values used as vegetable in Eastern Black Sea region of Turkey. Asian Journal of Plant Sciences, 5(2), 185-189.

Singleton, V.L., Orthofer, R. \& Lamuela-Raventós, R.M. (1999). Analysis of total phenols and other oxidation substrates and antioxidants by means of folin-ciocalteu reagent, Methods Enzymology, 299, 152-178. https://doi.org/10.1016/S00766879(99)99017-1

Şenkardeş, İ. \& Tuzlacı, E. (2016). Wild edible plants of southern part of Nevşehir in Turkey. Marmara Pharmaceutical Journal, 20, 34-43.

Temiz, M.A. (2021a). Antioxidant and antihyperglycemic activities of Scorzonera cinerea radical leaves in streptozocin-induced diabetic rats. Acta Pharmaceutica, 71(4), 603617. https://doi.org/10.2478/acph-2021-0045

Temiz, M.A. (2021b). Investigation of Phenolic composition, antioxidant capacity, and antidiabetic effect of Ornithogalum lanceolatum L.: An in vitro study. International Journal of Secondary Metabolite, 8(2), 91-100. https://doi.org/10.21448/ijsm.861904

Temiz, M.A. \& Temur, A. (2017). Effect of Solvent Variation on Polyphenolic Profile and Total Phenolic Content of Olive Leaf Extract. Yuzuncu
Yil University Journal of Agricultural Sciences, 27(1): 43-50.

Temiz, M.A. \& Temur, A. (2019). The effect of olive leaf extract on digestive enzyme inhibition and insulin production in streptozotocin-induced diabetic rats. Ankara Üniversitesi Veteriner Fakültesi Dergisi, 66, 163-169. https://doi.org/10.33988/auvfd.423491

WHO (World Health Organization) (2016). Global report on diabetes, Geneva: WHO press. Erişim adresi

https://apps.who.int/iris/bitstream/handle/10665/ 204871/9789241565257_eng.pdf;jsessionid=38 A1F1A6F019A1BB8C0A219810048AE2?sequ ence $=1$

WHO (World Health Organization) (2020). World health statistics 2020: monitoring health for the SDGs, sustainable development goals, Geneva: WHO press. Erişim adresi https://apps.who.int/iris/bitstream/handle/10665/ 332070/9789240005105-eng.pdf

Yang, K., Hashemi, Z., Han, W., Jin, A., Yang, H., Ozga, J., Li, L. \& Chan, C.B. (2015). Hydrolysis enhances bioavailability of proanthocyanidinderived metabolites and improves $\beta$-cell function in glucose intolerant rats. The Journal of Nutritional Biochemistry, 26, 850-859. https://doi.org/10.1016/j.jnutbio.2015.03.002

Yeşil, Y. \& İnal, İ. (2019). Traditional knowledge of wild edible plants in Hasankeyf (Batman Province, Turkey). Acta Societatis Botanicorum Poloniae, 88(3), 3633-3655. https://doi.org/10.5586/asbp.3633

Zhang, P., Li, T., Wu, X., Nice, E.C., Huang, C. \& Zhang, Y. (2020). Oxidative stress and diabetes: antioxidative strategies. Frontiers Med icine, 14(5), 583-600. https://doi.org/10.1007/s11684-019-0729-1

Zhishen, J., Mengcheng, T. \& Jianming, W. (1999). The determination of flavonoid contents in mulberry and their scavenging effects on superoxide radicals. Food Chemistry, 64, 555-559. https://doi.org/10.1016/S0308-8146(98)00102-2 